\title{
Residual Stress and Microstructure of Electroplated Cu Film on Different Barrier Layers
}

Alex A. Volinsky ${ }^{1}$, Meike Hauschildt ${ }^{2}$, Joseph B. Vella ${ }^{1}$, N.V. Edwards ${ }^{1}$, Rich Gregory $^{1}$, William W. Gerberich ${ }^{3}$

${ }^{1}$ Motorola DigitalDNA ${ }^{\mathrm{TM}}$ Labs, Process and Materials Characterization Lab, Mesa, AZ

${ }^{2}$ University of Texas, Materials Science Lab for Interconnect and Packaging, Austin, TX

${ }^{3}$ University of Minnesota, Dept. of Chem. Eng. and Materials Science, Minneapolis, MN

\section{ABSTRACT}

Copper films of different thicknesses between 0.2 and 2 microns were electroplated on adhesion-promoting TiW and Ta barrier layers on $\langle 100\rangle$ single crystal 6-inch silicon wafers. The residual stress was measured after each processing step using a wafer curvature technique employing Stoney's equation. Large gradients in the stress distributions were found across each wafer. Controlled $\mathrm{Cu}$ grain growth was achieved by annealing films at $350{ }^{\circ} \mathrm{C}$ for 3 minutes in high vacuum. Annealing increased the average tensile residual stress by about $200 \mathrm{MPa}$ for all the films, which is in agreement with stress-temperature cycling measurements.

After aging for 1 year wafer stress mapping showed that the stress gradients in the copper films were alleviated. No stress discrepancies between the copper on Ta and TiW barrier layers could be found. However, X-ray pole figure analysis showed broad and shifted (111) texture in films on a TiW underlayer, whereas the (111) texture in $\mathrm{Cu}$ films on $\mathrm{Ta}$ is sharp and centered.

\section{INTRODUCTION}

The microelectronics industry is gradually moving from $\mathrm{Al} / \mathrm{SiO}_{2}$ to $\mathrm{Cu} /$ lowK interconnect systems for improved performance. Currently one can buy a high-end processor from a leading semiconductor manufacturer such as Motorola that contains electroplated $\mathrm{Cu}$ interconnects. Although this is a tremendous achievement for the whole semiconductor industry, the continuing process of scaling requires further research and development regarding process improvements and reliability in metallization and dielectrics integration.

For the process control and most reliability tests, knowledge of the thin film constitutive mechanical behavior is required. Mechanical properties of thin films often differ from those of the bulk materials. This can be partially explained by the fine-grained structure of thin films and the fact that these films are attached to a substrate. The yield stress in thin films, for example, is typically much higher than for a bulk material. However in both cases the material microstructure can have a dramatic effect on the mechanical properties. Typically for bulk materials and in some cases for thin films as well, the grain size, $\mathrm{d}$ can affect the yield strength in a manner described by the Hall-Petch relation:

$$
\sigma_{Y S}=\sigma_{i}+k d^{-n}
$$

where $\sigma_{i}$ is some intrinsic stress, independent of the grain size $d$, and $n$ is typically between 0.5 and 1 . The classic $1 / d^{0.5}$ Hall-Petch relationship is not typically observed for thin films due to the substrate effect, limiting thin film plasticity, or due to the dislocation looping along the metal/oxide interface, both of which stem from the z-dimension of the film being the limiting 
geometrical factor for dislocation motion [1]. This being the case, the film thickness, $h$, can also be used instead of the grain size as the scaling parameter [2]:

$$
\sigma_{Y S}=\alpha\left[1+\beta h^{-1 / 2}\right]
$$

where $\alpha$ and $\beta$ are the fitting parameters. A similar approach, based on the film thickness is used by Nix [1] to predict $\mathrm{Cu}$ flow stress behavior. Due to typically high yield strengths thin films can support very high residual stresses. Thin film residual stress may have drastic effects on the device perfomance. Stress relief mechanisms through thin film plastic deformation, stress migration or interfacial delamination during processing or in the actual device operation lead to device failures. Stress gradients can also act as a driving force for vacancy motion and void coalescence in copper interconnects [3].

In addition to the mechanical properties, the microstructure of $\mathrm{Cu}$ interconnects, such as grain size and grain orientation, are likely to be important in determining its reliability, as has been observed in Al based interconnects [4]. Texture evolution and grain boundary concentration during and following electrodeposition in copper can have a determinant effect on vacancy diffusion, which can promote electromigration. [5]. Depending on the electroplating conditions and the type of barrier layer, this process results in a large variety of microstructures, mainly small grained and low textured [6-9]. Electroplated $\mathrm{Cu}$ is also known to self anneal at room temperature. In order to address issues related to reliability and process improvement, it is important to analyze the mechanical properties and the microstructure of $\mathrm{Cu}$ with respect to processing conditions, such as type and deposition of the barrier layer, plating conditions, stack geometry (e.g. film thickness) and post electroplating annealing steps.

This study reports results on the dependence of the residual stress and texture in electroplated $\mathrm{Cu}$ films on the barrier material and the thickness of the $\mathrm{Cu}$ film. Even though industry needs to understand the behavior of $\mathrm{Cu}$ in sub micron line structures, this study was conducted on blanket films, since the characteristics of films provide the basic background for understanding line structures.

\section{EXPERIMENT}

Copper films of different thicknesses of 0.2, 0.5, 1 and 2 microns were electroplated on top of the $\mathrm{Cu}$ seed layer on adhesion-promoting Ta or TiW barrier layers on $\langle 100\rangle$ 6-inch single crystal silicon wafers using copper sulfate bath with proprietary additives. To prevent room temperature grain growth due to self-annealing, films were annealed at $350{ }^{\circ} \mathrm{C}$ for 3 minutes in high vacuum. Some films were also annealed at temperatures below $300{ }^{\circ} \mathrm{C}$ for a longer time of 30 minutes.

The average residual biaxial stresses in the films can often be calculated from Stoney's equation by means of the wafer curvature technique:

$$
\sigma_{R}=\frac{E_{s}}{1-v_{s}} \frac{h_{s}^{2}}{6 h_{f} R}
$$

where $E_{s}$ is the elastic modulus of the substrate, and $v_{s}$ is the Poisson's ratio of the substrate, $h_{s}$ is the substrate thickness, $h_{f}$ is the film thickness, and $R$ is the radius of curvature of the substrate. The Young's modulus of the film is not required to evaluate the stresses in the film with this 
method. Typical test accuracy is within a $50 \mathrm{MPa}$ range. Stresses in thin films may vary by $50 \%$ throughout the wafer (Figure 1). Usually the film stress is not isotropic, and the substrate curvature varies in different directions, so equation 3 takes the following form:

$$
\sigma_{R}=\frac{E_{s}}{1-v_{s}} \frac{h_{s}^{2}}{6 h_{f} R_{1}} \cdot\left[1+\left[\frac{v}{1+v}\right] \cdot\left[\frac{R_{1}}{R_{2}}-1\right]\right]
$$

where $R_{1}$ and $R_{2}$ are the radii of curvature in the $\mathrm{x}-\mathrm{z}$ and y-z planes respectively. Substrate curvature radii can be measured accurately with laser deflection and optical lever cantilever beam techniques. This allows constructing a stress map over the whole wafer (Figure 1), although this is still a macroscopic average residual stress that is calculated. The film residual stress was measured using FSM 128 stress measurement system [10]. FSM 128 performs 12 scans of the surface of a wafer before and after the film deposition. Local stress is calculated employing equation 4. Electroplated $\mathrm{Cu}$ film mechanical properties were evaluated with the Nanoindenter $\mathrm{XP}^{\mathrm{TM}}$, using a sharp $(<100 \mathrm{~nm}$ tip radius) Berkovich tip and the continuous stiffness modulation (CSM) option, and with the Hysitron TriboScope. Elastic modulus and hardness are the two properties that can be readily extracted from the nanoindentation loaddisplacement curve [11-13]. Results have been reported in previous studies [14]. Although films of the same thickness on Ta and TiW barrier layers have the same elastic modulus, the hardness of $\mathrm{Cu}$ films on $\mathrm{Ta}$ about $50 \mathrm{MPa}$ lower than on TiW.

Copper films grain size was measured from Focused Ion Beam images. To characterize the texture in the films, X-ray pole figure measurements were performed with a capillary tube source on a Bede D1 High-Resolution X-ray diffractometer. The power setting for the X-ray source was $40 \mathrm{kV} / 2 \mathrm{~mA}$. The (111), (200) and (220) pole figures were measured. The sample was rotated around Chi from $0^{\circ}$ to $85^{\circ}$ and around Phi from $0^{\circ}$ to $360^{\circ}$ with a step of $5^{\circ}$.

\section{DISCUSSION}

Stress maps of a Ta/Cu film during different stages of processing are shown in Figure 1. Note a high stress variation across the wafer (200-300 MPa) in the Ta and Cu layers after processing. Upon cutting a die out of the wafer the stress is only insignificantly relieved locally at the edges of the die, and almost the same residual local stress levels will result in each particular layer in the middle of a die as on the stress maps of the whole wafer.

It was also interesting to see that the residual stress increased after annealing (compare Figure $1 \mathrm{~b}$ and Figure 1c). This was observed on all $\mathrm{Cu}$ films of various thicknesses on both Ta (Figure 2a) and TiW underlayers. During annealing at $350^{\circ} \mathrm{C}$ the stresses in the film relax toward a zero stress state. Upon cooling, the mismatch between the thermal expansion coefficients of the film and the substrate lead to an increase in tensile stress in the film. However, most of this stress is accommodated plastically $[1,14,15]$; otherwise complete elastic behavior upon cooling would result in residual stresses on the order of $800 \mathrm{MPa}$, which is not observed (Figure 2b). The final residual stress is about $200 \mathrm{MPa}$ higher after the first heating/cooling cycle, as can be concluded from both post-annealing stress and stress-temperature measurements (Figure 2). In agreement with previous studies [1], the residual stress in thinner films is higher. Plastic deformation occurs to a smaller extent in thinner films, since more energy is needed for dislocations to move through the film. After one year, significant changes in the stress states of $\mathrm{Cu}$ films were observed. $\mathrm{Cu}$ residual stress relaxed slightly and evened out across the wafer (compare Figure 1c and Figure 
1d). This can be explained by stress migration through gradient vacancy redistribution and/or low temperature creep. The stress values before and after annealing do not show any significant differences between the samples with a Ta or a TiW underlayer suggesting that the interaction of the $\mathrm{Cu}$ film and the thick substrate are not influenced by the very thin barrier layer.

The grain size as well as the hardness in Cu films has been characterized and the results have been reported in our previous paper along with the analysis of the yield strength [14]. No significant differences in the mechanical properties are found for the films of the same thickness on two different barrier layers. In the present study we found that the longer anneal time even at lower temperatures results in a similar film grain size, almost independent of the film thickness. Although both equations 1 and 2 can be used to predict $\mathrm{Cu}$ yield stress behavior as a function of the film thickness and the grain size, we believe that the film thickness approach of Wei and Hutchinson [2] is more appropriate for films with the grain size larger than the film thickness.
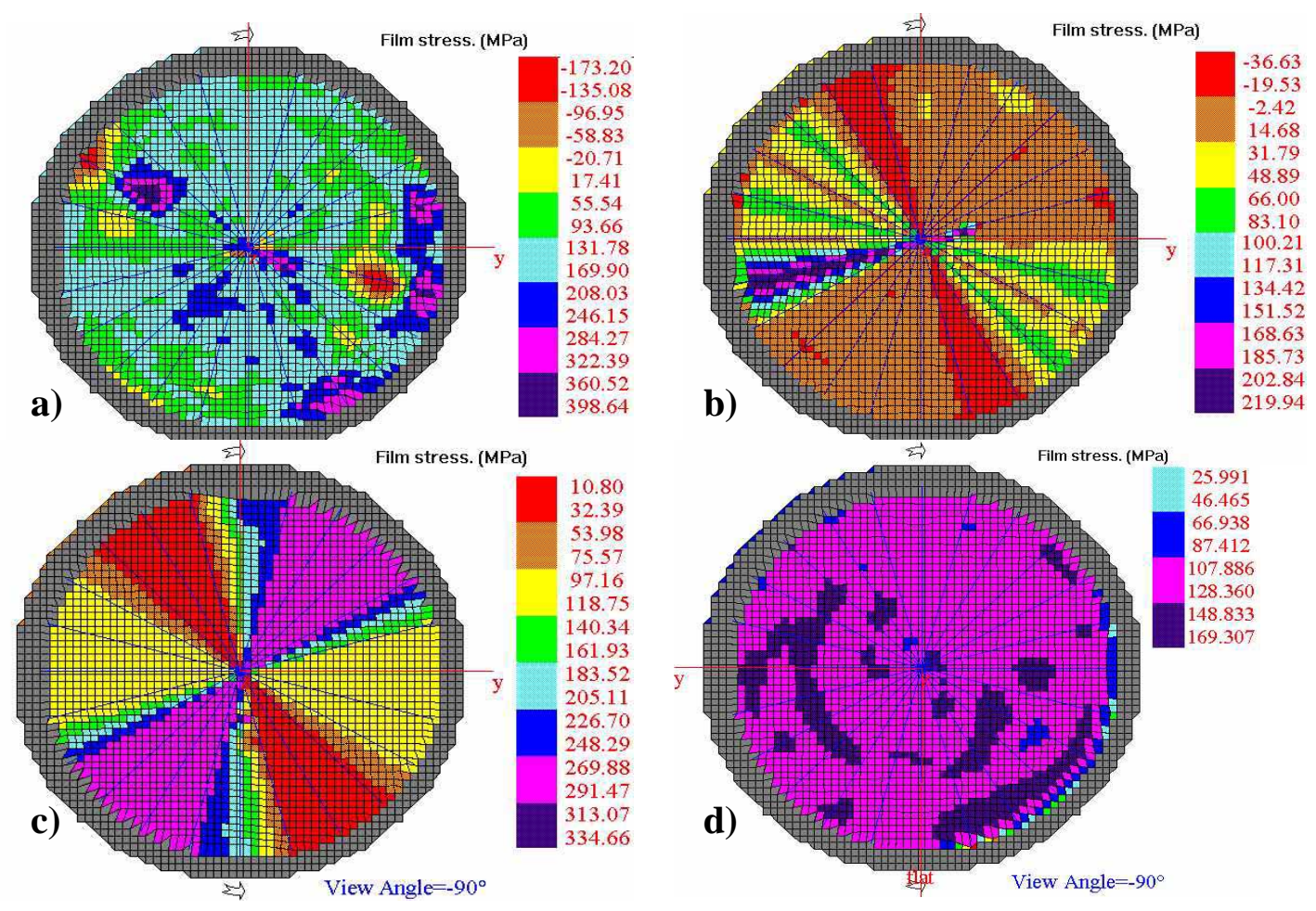

Figure 1. Stress map of: a) $75 \mathrm{~nm}$ Ta $100 \mathrm{~nm} \mathrm{Cu}$ seed layer; b) As-plated $2 \mu \mathrm{m} \mathrm{Cu}$ film on top of film a); c) $2 \mu \mathrm{m} \mathrm{Cu}$ electroplated film right after annealing; d) Same $\mathrm{Cu}$ film aged for 1 year.
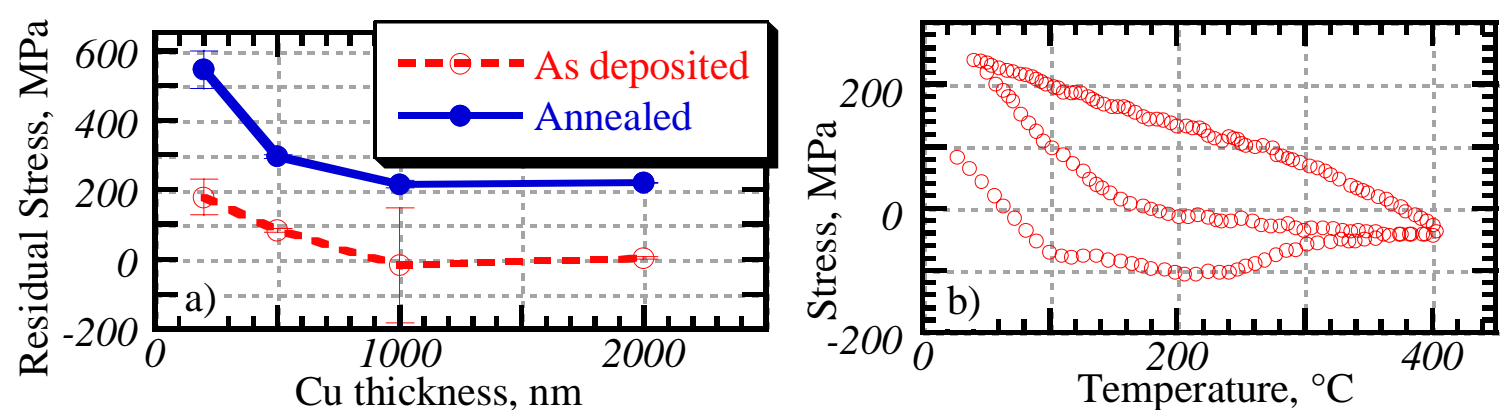

Figure 2. a) Residual stress of $\mathrm{Cu}$ thin film on $\mathrm{Ta}$, error bars represent measurements from two different wafers for the same film thickness; b) Stress-temperature cycling of a $1 \mu \mathrm{m} \mathrm{Cu}$ film. 
A texture study revealed significant differences between $\mathrm{Cu}$ films on a Ta underlayer compared to a TiW barrier. (111) pole figures of $\mathrm{Cu}$ on $\mathrm{Ta}$ and $\mathrm{TiW}$ are shown in Figure 3. $\mathrm{Cu}$ films on a Ta underlayer show a sharp (111) texture, no (200) texture component and orientations due to multiple twin formation (Figure 3a). It is well known that electroplated $\mathrm{Cu}$ films show a high tendency towards twinning. The orientation relationship between the original grain and its twin can be calculated $[16,17]$ and consistency with the location of some rings in the pole figures can be shown. We observe that in contrast to the films on a Ta barrier layer, the films on a TiW underlayer have a (111) and a weaker (200) texture component which are both broad and shifted off the sample normal position (Figure 3b). A tilt of the (111) with respect to the sample normal does not seem energetically favorable, however could possibly be a result of the underlayer. A dependence of texture on underlayer has been observed by other researchers $[18,19]$ and seems to depend not only on the materials used, but also the processing conditions. The $\mathrm{Cu}$ seed layer seems to adopt the microstructure of the underlying barrier layer. Tracy et al. discovered a stronger (111) texture in a sputtered $\mathrm{Cu}$ film deposited on a highly textured $\mathrm{Ti}$ underlayer compared with that deposited on a weakly textured TiN layer [18]. Likewise the electroplated $\mathrm{Cu}$ film adopts the microstructure from the underlying seed layer. Rosenberg reported a stronger (111) texture in a plated $\mathrm{Cu}$ film on a (111) textured PVD $\mathrm{Cu}$ seed compared to a film on a randomly oriented CVD Cu seed [6]. Hence it is possible that the tilt of the (111) and the (200) grains in $\mathrm{Cu}$ films on a TiW layer are related to the microstructure and surface morphology of the TiW. Since a TiW film is known to be significantly rougher than a Ta film, terrace or facet growth during processing as a result of the underlayer might be occurring. Thorough analysis of the barrier layer and the $\mathrm{Cu}$ seed layer is required to verify this hypothesis. The shift and broadness of the (111) and (200) peaks in the films on TiW decreases with decreasing $\mathrm{Cu}$ film thickness. Likewise in the $\mathrm{Cu}$ films on Ta, the fraction of (111) oriented grains is larger in thinner films. It seems that thinner films show a stronger and tighter orientation distribution. At his point X-ray pole figure analysis is the only technique that showed the difference in electroplated $\mathrm{Cu}$ films properties in different underlayers, in terms of the microstructure, residual stress and the mechanical properties these films are very similar.
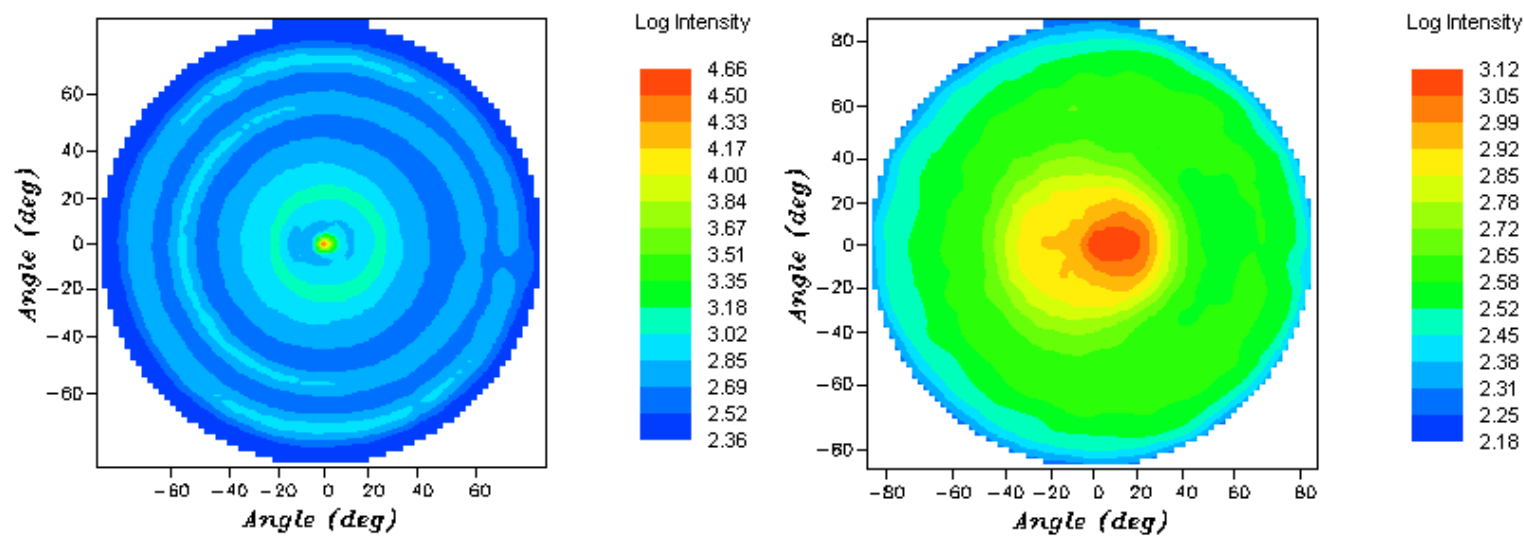

Figure 3. (111) Pole figures of a $1 \mu \mathrm{m} \mathrm{Cu}$ film on a) Ta underlayer and b) TiW underlayer sowing peak shift. 


\section{CONCLUSIONS}

The microstructural properties of electroplated $\mathrm{Cu}$ films are shown to depend significantly on the underlayer, the film thickness, and the processing conditions. The low residual tensile stress as deposited increases significantly after annealing at $350{ }^{\circ} \mathrm{C}$. During the course of a year, the stresses relax slightly and become increasingly uniform over the whole wafer. In agreement with previous studies, thinner $\mathrm{Cu}$ films show larger values of residual stress, hardness and (111) texture. The thin underlayer does not seem to influence the stress states in the film significantly, which are mainly determined by the interaction of the film and the thick substrate. Mechanical properties of these films appear similar for the same film thickness. However, we observe a substantial variation in the orientation distribution showing a broad and shifted (111) texture in films on a TiW underlayer, whereas the (111) texture in $\mathrm{Cu}$ films on Ta is sharp and centered.

\section{ACKNOWLEDGEMENTS}

Authors would like to acknowledge support of John D'urso, Steven Smith, Jeff Baker and Stephen Lee from Motorola.

\section{REFERENCES}

1. W.D. Nix, Metall. Trans. A, 20A, pp. 2217-2245, (1989)

2. Y. Wei and J.W. Hutchinson, J. Mech. Phys. Solids, 45 (7), pp. 1137-1159, (1997)

3. D.D. Brown, P. Borgesen, D.A. Lilienfeld, M.A. Korhonen and C.Y. Li, Mat. Res. Soc. Symp. Proc. Vol. 239, pp. 701-706, (1993)

4. H. Toyoda, P.-H. Wang, P. S. Ho, in Proceedings of the International Reliability Physics Symposium in 1998, (IEEE, Piscataway, 1998), pp. 324-328.

5. E. Zschech, W. Blum, I Zienert, P. R. Besser, Z Metallkd. 92, pp. 803-809, (2001)

6. R. Rosenberg, D. C. Edelstein, C.-K. Hu, K. P. Rodbell, Annual Review of Materials Sciences, (2000)

7. K. Ueno, T. Ritzdorf, S. Grace, J. Appl. Phys. 86 (9), pp. 4930-4935, (1999)

8. S. H. Brongersma, E. Richard, I. Vervoort, H. Bender, W. Vandervorst, S. Lagrange, G. Beyer, K. Maex, J. Appl. Phys. 86 (7), pp. 3642-3645, (1999)

9. M. Hauschildt, M.S. thesis, The University of Texas at Austin, (1999)

10. Frontier Semiconductor Measurements Inc., FSM 128\&128L Operation Manual Rev. 4/98

11. M. Doerner and W. Nix, J. Mater. Res. 1, p. 601, (1986)

12. G.M. Pharr, W.C. Oliver, F. Brotzen, J. Mater. Res., 7 (3), pp. 613-617, (1992)

13. W.C. Oliver and G.M. Pharr, J. Mater. Res., 7, pp.1564-1583, (1992)

14. A.A. Volinsky, J. Vella, I.S. Adhihetty, V. Sarihan, L. Mercado, B.H. Yeung, W.W. Gerberich, Mat. Res. Soc. Symp. Proc. Vol. 649, (2000)

15. R.P. Vinci, E.M. Zielinski, J.C. Bravman, Thin Solid Films 262, pp. 142-153, (1995)

16. G. Gottstein, Acta Metall. 32 (7), 1117-1138, (1984)

17. M. Hauschildt, E. T. Ogawa, S.-H. Rhee, D. Gan, P. S. Ho, to be published in Mater. Res. Soc. Symp. Proc., (2001)

18. D. P. Tracy, D. B. Knorr, K. P. Rodbell, J. Appl. Phys. 76 (5), (1994) pp. 2671-2680

19. E. M Zielinski, Ph. D. thesis, Stanford University, (1995) 